\title{
A laboratory experiment of intact polar lipid degradation in sandy sediments
}

\author{
J. Logemann*, J. Graue*, J. Köster, B. Engelen, J. Rullkötter, and H. Cypionka \\ Institute for Chemistry and Biology of the Marine Environment (ICBM), Carl von Ossietzky University of Oldenburg, \\ P.O. Box 2503, 26111 Oldenburg, Germany \\ * These authors contributed equally to this work. \\ Received: 7 March 2011 - Published in Biogeosciences Discuss.: 24 March 2011 \\ Revised: 26 August 2011 - Accepted: 3 September 2011 - Published: 13 September 2011
}

\begin{abstract}
Intact polar lipids (IPLs) are considered biomarkers for living biomass. Their degradation in marine sediments, however, is poorly understood and complicates interpretation of their occurrence in geological samples. To investigate the turnover of IPLs, a degradation experiment with anoxic sandy sediments from the North Sea was conducted. Intact cells of two organisms that do not naturally occur in North Sea sediments were chosen as IPL sources: (i) Saccharomyces cerevisiae, representative for ester-bound acyl lipids that also occur in Bacteria, and (ii) the archaeon Haloferax volcanii, representative for ether-bound isoprenoid lipids. Surprisingly, IPLs with phosphoester-bound head groups showed approximately the same degradation rate as IPLs with glycosidic head groups. Furthermore, the results indicate a relatively fast degradation of $S$. cerevisiae IPLs with ester-bound moieties (analogs of bacterial membrane lipids) and no significant degradation of archaeal IPLs with etherbound moieties. Pore water and 16S rRNA-based DGGE analysis showed only a minor influence of the IPL source on microbial metabolism and community profiles. Due to our results, the IPL-based quantification of Archaea and Bacteria should be interpreted with caution.
\end{abstract}

\section{Introduction}

Intact polar lipids (IPLs) have widely been used as biomarkers for living organisms in sediments and water columns for several years (e.g. Zink et al., 2003; Sturt et al., 2004; Biddle et al., 2006; Ertefai et al., 2008; Rossel et al., 2008; Schubotz et al., 2009; Van Mooy et al., 2009). Addition-

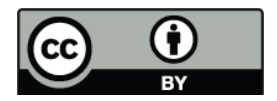

Correspondence to: J. Logemann (j.logemann@icbm.de) ally, IPLs are applied as chemotaxonomic markers as some of these molecules are representative for specific microbial clades. The chemotaxonomic information of IPLs is based on the combination of various head groups with different side chains that are attached to a glycerol backbone by two different bonding types. In general, bacterial and eukaryal cytoplasma membranes contain intact polar lipids with nonisoprenoidal ester-bound fatty acid moieties. In contrast, archaeal IPLs contain ether-bound isoprenoid moieties. This difference between bacterial and archaeal IPLs has been used to quantify Bacteria and Archaea in sediments and water samples (e.g. Rossel et al., 2008; Lipp et al., 2008; Schubotz et al., 2009; Van Mooy et al., 2009). Thus, IPL analysis is valuable as an alternative or complementary technique to standard microbiological methods. On a higher chemotaxonomic level, ammonia-oxidizing bacteria can be identified by the presence of ladderane lipids (Bouman et al., 2006; Jaeschke et al., 2009). Intact polar lipids with mixed ether/ester-bound moieties attached to the glycerol backbone were found in some strains of sulfate-reducing bacteria (Rütters et al., 2001). Separate $\delta^{13} \mathrm{C}$ analysis of polar head groups or non-polar core lipids of IPLs can be used to gain information on the metabolism of their producers (Boschker et al., 1998; Lin et al., 2010; Takano et al., 2010).

One fundamental assumption underlies most of these applications: intact polar lipids are considered to degrade rapidly after cell death (White et al., 1979; Harvey et al., 1986). Harvey et al. (1986) examined the degradation of both, a glycosidic ether lipid and ester-bound phospholipids. Based on their findings, the authors assumed that intact polar lipids with glycosidic head groups show a higher stability against degradation than intact polar lipids with phosphoester head groups. Following the results of Harvey et al. (1986), Lipp and Hinrichs (2009) and Schouten et al. (2010) modeled the potential preservation of fossilized IPLs of planktonic

Published by Copernicus Publications on behalf of the European Geosciences Union. 
origin after sediment burial. Using different variables significantly influenced the results showing that modeling alone cannot resolve the preservation issue and that experimental data are needed.

The quantification of Bacteria and Archaea in the deep marine biosphere by IPL analysis and fluorescence in situ hybridization (FISH) in comparison to catalyzed reporter deposition fluorescence in situ hybridization (CARD-FISH) and quantitative polymerase chain reaction (q-PCR) analysis has been controversially discussed in several studies (e.g. Schippers et al., 2005; Biddle et al., 2006; Lipp et al., 2008). A reason for the contradictory abundances of Archaea and Bacteria in these studies may be that ether-bound archaeal IPLs are more stable than their ester-bound bacterial counterparts, which in turn may lead to an overestimation of archaeal cell numbers. On the other hand, q-PCR-based investigations may underestimate the yields of archaeal 16S rRNA genes, as indicated by Lipp et al. (2008) and Teske and Sørensen (2008). However, the lack of a broad study on the degradation of intact polar lipids, which includes lipids with phosphoester and glycosidic head groups as well as ester- and ether-bound moieties occurring in Bacteria and Archaea, respectively, makes it necessary to revisit the degradation of IPLs to ensure the robustness of this proxy.

We designed a degradation experiment to answer three general questions: what are the degradation rates of IPLs? Are there differences between ester- and ether-bound intact polar lipids and what is the influence of the bonding type of the head group upon lipid degradation? The main degradation experiment was accompanied by two controls: the first control was intended to assess any processes that are not mediated by microorganisms but still lead to the degradation of the added IPLs. This control is subsequently named "abiotic control". No cell material was added to the second control. It was used to investigate the development of the microbial community without any further substrate addition under laboratory conditions. This control is subsequently named "untreated control".

\section{Material and methods}

\subsection{Experimental setup}

The incubation vessels for the degradation experiment and the untreated control had a total volume of 2.51 each and were filled with $3 \mathrm{~kg}$ wet sediment (water content $29 \% \mathrm{wt}, 2.13 \mathrm{~kg}$ dry wt). The sediment used in this experiment had been freshly collected in November 2009 on Janssand, a sandplate located approximately $3 \mathrm{~km}$ south of Spiekeroog Island, North Sea, Germany $\left(53^{\circ} 44.178^{\prime} \mathrm{N}\right.$ and $07^{\circ} 41.974^{\prime} \mathrm{E}$ ). For sampling, the top centimeter of oxic surface sediment was removed until only black anoxic sediment was visible. The underlying sediment was transferred into plastic containers, which were sealed by a lid, trans- ported to the laboratory and stored at $4{ }^{\circ} \mathrm{C}$ for one week prior to further use. The total organic carbon (TOC) content was $0.23 \%$. It was calculated as the difference between total carbon (Vario EL Cube, Elementar Analysensysteme $\mathrm{GmbH}$, Germany) and inorganic carbon (UIC CO 2 coulometer). The pore water concentration of sulfate was equal to the sea water concentration $(28 \mathrm{mM})$. A total of $2.5 \mathrm{~g}$ Saccharomyces cerevisiae biomass (elemental composition, of dry mass: $45.1 \% \mathrm{C}, 7.9 \% \mathrm{H}, 7.9 \% \mathrm{~N}$ and $0.4 \% \mathrm{~S}$ ) as source for ester-bound IPLs and $1.25 \mathrm{~g}$ of Haloferax volcanii $(18.9 \% \mathrm{C}$, $3.6 \% \mathrm{H}, 4.7 \% \mathrm{~N}$ and $0.7 \% \mathrm{~S}$ ) as source for ether-bound IPLs were added to the sediment in the incubation vessels used to study IPL degradation.

As calculated from the equation of Adams et al. (1990), the dry weight of a single Saccharomyces cerevisiae cell is approximately $60 \mathrm{pg}$. With a total sediment volume of $1.512 .8 \times 10^{7}$ cells ml$^{-1}$ sediment were added. The cell size of a single Haloferax volcanii cell is $1-3 \times 2-3 \mu \mathrm{m}$ and $0.4-0.5 \mu \mathrm{m}$ thick (Mullakhanbhai and Larsen, 1975). Assuming a water content of $80 \%$, this leads to a dry weight of $0.16-0.9 \mathrm{pg}$ per single cell of Haloferax volcanii. With $1.25 \mathrm{~g}$ of dry Haloferax biomass, approximately $9.3 \times 10^{8}$ $5.2 \times 10^{9}$ cells ml$^{-1}$ were added. The elemental composition of the dry biomass used in this experiment indicates a contamination with inorganic material. Thus, the calculated cell number may be too high but still in the correct order of magnitude. After addition of cell material to the incubation vessel, the sediment was homogenized for $6 \mathrm{~h}$ on a mixing device by slow rotation $(12 \mathrm{rpm})$. The experimental parameters for the untreated control were the same as for the degradation experiment but no inactive cell material was added. To prevent contamination with microorganisms due to sampling, several $100 \mathrm{ml}$ bottles were used instead of a single 2.51 incubation vessel for the abiotic control. The bottles contained $50 \mathrm{~g}$ of sediment, $50 \mathrm{mg}$ dry inactive biomass of $S$. cerevisiae and $25 \mathrm{mg}$ dry inactive $H$. volcanii biomass and were closed with rubber stoppers. The incubation vessels of the abiotic control were autoclaved after addition of the intact polar lipid-containing cell material.

\subsection{Source material for intact polar lipids}

As sources for intact polar lipids, two different organisms were used which do not occur in North Sea sediment. Etherderived IPLs (diphytanylglycerols $=$ DPGs) were originated from pure culture of Haloferax volcanii (DSM No. 16227) grown at $37^{\circ} \mathrm{C}$ in "Haloferax sulfurifontis medium" (DSMZ No. 1018). This archaeon provided two kinds of structurally different molecules - first, two IPLs with ether-bound isoprenoid moieties and a phosphoester head group (PGP-MeDPG, PG-DPG; Fig. 1) and second, an IPL with ether-bound isoprenoid moieties and a glycosidic head group (S-GL-1DPG; Fig. 1). The cells were harvested at the end of the exponential growth phase. None of the $H$. volcanii IPLs occur in the natural sediment and thus all of them could be used 


\section{Core lipids}

A

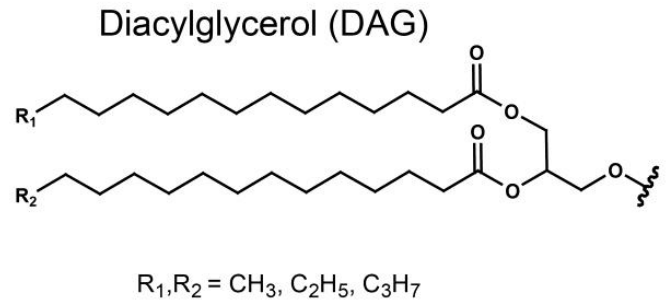

B

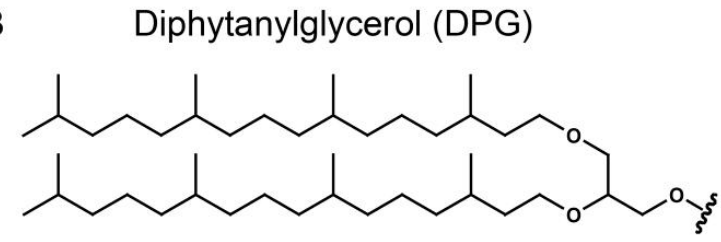

\section{Head groups}
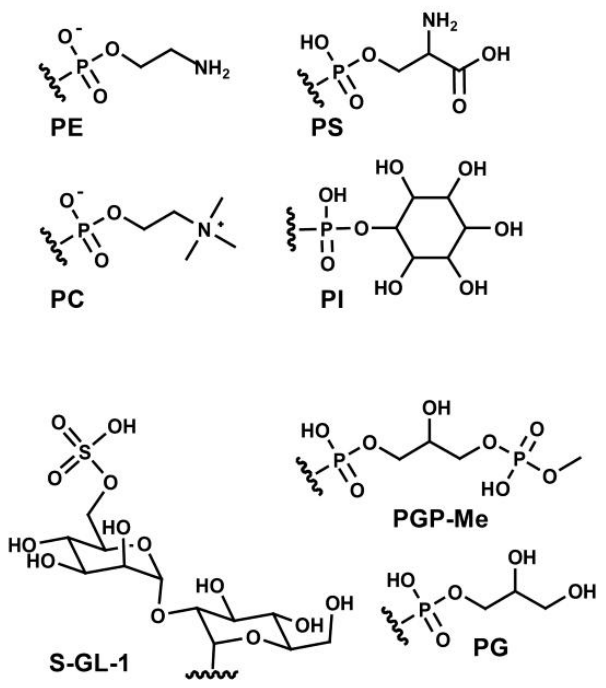

Fig. 1. Chemical structures of IPLs characteristic for the two organisms used in this study: (A): diacylglycerol ester-bound core lipids (DAGs) of Saccharomyces cerevisiae bound to: phosphatidylethanolamine (PE), phosphatidylcholine (PC), phosphatidylinositol (PI) and phosphatidylserine (PS); (B): diphytanylglycerol ether-bound core lipids (DPGs) of Haloferax volcanii bound to: sulfono diglyco dialkylglycerol S-GL-1 (nomenclature according to Sprott et al., 2003), phosphatidylglycerol (PG) and phosphatidylglycerol methylphosphate (PGP-Me).

as tracers to monitor the degradation of ether-bound IPLs. Commercially available Saccharomyces cerevisiae (baker's yeast; Fala GmbH, Germany) was used as source for IPLs with ester-bound acylic moieties (diacylglycerols $=$ DAGs) and phosphoester head groups. S. cerevisiae cells harbor a broad variety of IPLs which were partly used as tracers because these IPLs are not synthetized by the natural sediment microbial community. S. cerevisiae and the harvested archaeal cells were freeze-dried and stored at $-20^{\circ} \mathrm{C}$. Before use in the experiment, $H$. volcanii and $S$. cerevisiae cells were pasteurized at $100^{\circ} \mathrm{C}$ for $30 \mathrm{~min}$. Thereafter, part of the cells was transferred to fresh medium ("Haloferax sulfurifontis medium" and yeast extract medium, respectively) to confirm that the cells were no longer alive and unable to grow.

Identification of $S$. cerevisiae lipids was achieved by HPLC-MS/MS experiments and comparison of mass spectral data to commercially available standards. The lipids of $H$. volcanii were identified by MS/MS experiments and comparison with published results of lipid structures (Sprott et al., 2003). In this experiment we monitored the contents of 16 intact polar lipids, 13 of them were ester-bound and 3 ether-bound.

\subsection{Incubation parameters and sampling}

After starting the experiment, the incubation vessels were stored at room temperature in the dark. Before sampling, the sediment was homogenized for a minimum of $20 \mathrm{~min}$ on a mixing device. Headspace gas samples were taken with a syringe directly before sampling the sediment. For sediment and pore water sampling, the incubation vessels were transferred into a glove box with an oxygen-free nitrogen $(99 \%)$ and hydrogen $(1 \%)$ atmosphere. Samples were taken as triplicates, aliquots of $8-12 \mathrm{~g}$ sediment for IPL analysis and 3-5 g sediment for RNA extraction. Pore water (1-2 ml) was extracted with rhizones (Rhizon CSS $5 \mathrm{~cm}$, Rhizosphere Research Products, Wageningen, The Netherlands) from the samples that were collected for IPL analysis. Our previous investigations had ensured the absence of IPLs in the pore water samples (data not shown). Until further processing, all samples were stored at $-20^{\circ} \mathrm{C}$. The samples for RNA extraction were kept at $-80^{\circ} \mathrm{C}$. After sampling, the headspace of the incubation vessels was flushed with nitrogen to remove traces of hydrogen that was used in the glove box to sustain the oxygen-free atmosphere. The constantly increasing $\mathrm{pH}$ was adjusted at each sampling point to values between 7 and 7.5 by addition of hydrochloric acid. After day 21, sulfate concentrations were adjusted to approximately $28 \mathrm{mM}$ by the addition of $1 \mathrm{M} \mathrm{Na}_{2} \mathrm{SO}_{4}$ when concentrations dropped below $10 \mathrm{mM}$. After day 76, when hydrogen sulfide reached toxic concentrations, it was expelled by flushing the headspace with $\mathrm{CO}_{2}$. After each $\mathrm{CO}_{2}$ flushing the headspace was replaced with $\mathrm{N}_{2}$. 


\subsection{Lipid extraction}

Wet sediment was extracted using the Bligh \& Dyer method modified according to Sturt et al. (2004). In the first three extraction steps, a single-phase mixture of methanol, dichloromethane and phosphate buffer $(2: 1: 0.8, v / v / v)$ was used. In the following three extraction steps, trichloroacetic acid replaced the phosphate buffer. The combined extracts were collected in a separatory funnel. Phase separation was achieved by addition of dichloromethane and water to a final mixture of 1:1:0.9 ( $/ / v / v$, methanol, dichloromethane, aqueous phase). The organic phase containing the IPLs was removed and the aqueous phase washed three times with dichloromethane. The dry extracts were stored in a freezer at $-20^{\circ} \mathrm{C}$ until further use.

\subsection{HPLC-MS}

Intact polar lipids were analyzed by HPLC (2695 separation module, Waters, Milfort, USA) coupled to a timeof-flight mass spectrometer equipped with an electrospray source (Micromass, Q-TOF micro, Waters, Milfort, USA). HPLC separation was achieved on a diol phase (Lichrospher100 Diol $5 \mu \mathrm{m}, \mathrm{CS}$ - Chromatographie Service, Langerwehe, Germany) using a $2 \times 125 \mathrm{~mm}$ column. A flow rate of $0.35 \mathrm{ml} \mathrm{min}^{-1}$ was employed with the following solvent gradient: $1 \mathrm{~min} 100 \% \mathrm{~A}$, increasing over $20 \mathrm{~min}$ to $35 \% \mathrm{~A}$, $65 \% \mathrm{~B}$ using a concave curvature, followed by $40 \mathrm{~min}$ of reconditioning (Rütters et al., 2001). Eluent A was a mixture of $n$-hexane, $i$-propanol, formic acid and a solution of $25 \%$ ammonia in water (79:20:1.2:0.04 by volume), eluent B was $i$-propanol, water, formic acid and a solution of $25 \%$ ammonia in water (88:10:1.2:0.04 by volume). After addition of an injection standard (O-PE, phosphatidyl ethanolamine diether with two $\mathrm{C}_{16}$ alkyl moieties) to every sample, the extracts were dissolved in the starting eluent and directly analyzed. In this study, we exclusively report the change of those compounds that were added with the inactive cell material and did not occur in the natural sediment. Due to the lack of analytical standards for the archaeal glycolipids used, it was not possible to determine the absolute concentrations of these compounds. Instead, ratios of peak areas of the monitored compounds to the peak area of the injection standard for each sample were calculated. To compare the results of esterbound and ether-bound IPLs the same procedure was applied also to Saccharomyces-derived IPLs. Peak areas were determined by integration of mass traces. Since all samples had the same matrix background, this procedure should give reasonable results without any influence of changing ionization. The analytical error varied between $0.5 \%$ and $7 \%$ depending on the investigated IPL and was determined by repeated analysis of the same samples taken at three different times. The limit of detection in general depends on the ionization efficiency for every analyzed compound and typically lies between 2 and 10 ng per injection and IPL for the mass spectrometer used.

\subsection{Chemical analyses}

Sulfate concentrations were measured by an ion chromatograph with an LCA A24 anion separation column (both Sykam, Fürstenfeldbruck, Germany) at $60^{\circ} \mathrm{C}$ followed by conductivity detection. The eluent consisted of $0.64 \mathrm{~g}$ sodium carbonate, $0.2 \mathrm{~g}$ sodium hydroxide, $150 \mathrm{ml}$ ethanol and $2 \mathrm{ml}$ modifier $(0.1 \mathrm{~g}$ 4-hydroxybenzonitrile $/ 10 \mathrm{ml}$ methanol) filled up to 11 with distilled water. The flow rate was set to $1.2 \mathrm{ml} \mathrm{min}^{-1}$. Prior to analysis the samples were diluted 1:100 in eluent without modifier.

The concentrations of gaseous compounds were determined by an $8610 \mathrm{C}$ gas chromatograph (Schambeck SFD $\mathrm{GmbH}$, Honnef, Germany). Analysis was carried out with argon $\left(1 \mathrm{ml} \mathrm{min}^{-1}\right)$ as carrier gas and at a column oven temperature of $40^{\circ} \mathrm{C}$. For analysis of molecular hydrogen and methane a molecular sieve $13 \mathrm{X}$ packed column was used, whereas carbon dioxide was separated by a HayeSep D packed column. A thermal conductivity detector $\left(256^{\circ} \mathrm{C}\right)$ and a flame ionization detector $\left(380^{\circ} \mathrm{C}\right)$ were connected in series for detection of the gases.

Sulfide concentrations were determined photometrically as described by Cord-Ruwisch (1985).

\subsection{Calculation of degradation rates}

Degradation rates were calculated with the following equation described by Schouten et al. (2010):

$C_{t}=C_{\mathrm{i}} \cdot e^{-k^{\prime} t}$,

with $C_{t}=$ concentration at time $t, C_{\mathrm{i}}=$ initial concentration and $k^{\prime}$ being the kinetic degradation constant. This method allows calculating degradation rates from degradation curves without curve fitting. The degradation constants $k^{\prime}$ were calculated for every time point separately using data of day zero and the respective time point. Values for the calculation of degradation rates of phosphatidylethanolamine diacylglycerol (PE-DAG) and glycol diphytanylglycerol (GLDPG) were taken from Figs. 2 and 3 (beach sediments) in Harvey et al. (1986). For calculating degradation rates of IPLs investigated in this study, we used mean values of esterand ether-bound IPLs. Due to increasing contents of esterand ether-bound IPLs, no degradation rates could be calculated for the first 5 and first 9 days, respectively.

\subsection{Determination of total cell numbers}

Total cell counts were obtained after SYBR Green I staining (Molecular Probes, Eugene, OR, USA) according to a protocol of Lunau et al. (2005), which was adapted to sediment samples. For sample fixation, $0.5 \mathrm{~cm}^{3}$ of sediment was transferred to $4.5 \mathrm{ml}$ of fixing solution $(63 \mathrm{ml}$ distilled water, 
$30 \mathrm{ml}$ methanol, $2 \mathrm{ml}$ of $25 \%$ aqueous glutardialdehyde solution, $5 \mathrm{ml}$ Tween 80) and incubated at room temperature overnight. For detaching cells from particles, the sediment slurries were incubated for $15 \mathrm{~min}$ at $35^{\circ} \mathrm{C}$ in an ultrasonic bath $(35 \mathrm{kHz}, 2 \times 320 \mathrm{~W}$ per period; Sonorex RK $103 \mathrm{H}$, Bandelin, Mörfelden-Walldorf, Germany). Homogenized aliquots of $20 \mu \mathrm{l}$ were equally dispensed on a clean microscope slide in a square of $20 \times 20 \mathrm{~mm}$. The slide was dried on a heating plate at $40^{\circ} \mathrm{C}$. A drop of $12 \mu \mathrm{l}$ staining solution (190 $\mu \mathrm{l}$ Moviol, $5 \mu \mathrm{l} \mathrm{SYBR}$ Green I, $5 \mu \mathrm{l} 1 \mathrm{M}$ ascorbic acid in TAE buffer) was placed in the center of a $20 \times 20 \mathrm{~mm}$ coverslip, which was then placed on the sediment sample. After 10 min of incubation, 20 randomly selected fields or at least 400 cells were counted for each sediment sample by epifluorescence microscopy.

\subsection{RNA extraction and quantification}

Total RNA was extracted from $1 \mathrm{~g}$ sediment using the AllPrep DNA/RNA Mini Kit (Qiagen, Hilden, Germany) according to the manufacturer's instructions. For cell disruption, $1 \mathrm{~g}$ sediment and $1 \mathrm{ml}$ RLT Buffer were added to $1 \mathrm{~g}$ glass beads $(0.18 \mathrm{~mm}$ diameter, Sartorius, Göttingen, Germany). Samples were homogenized for $90 \mathrm{~s}$ using a Mini Beadbeater (Biospec Products, Bartlesville, USA).

For quantification, $100 \mu \mathrm{l}$ of RiboGreen (Invitrogen, Eugene, USA) solution (diluted 1:200 in TE buffer; $\mathrm{pH}$ 7.5) were added to $100 \mu \mathrm{l}$ of RNA extract (each sample diluted 1:100 in TE buffer; $\mathrm{pH} 7.5$ ) and transferred to a microtiter plate. Serial dilutions (200 to $1 \mathrm{ng} \mu^{-1}$ ) of E. coli $16 \mathrm{~S}$ and 23S ribosomal RNA (Roche, Grenzach-Wyhlen, Germany) were treated as described above and served as a calibration standard in each quantification assay. Fluorescence was measured at an excitation of $485 \mathrm{~nm}$ and an emission of $520 \mathrm{~nm}$.

\subsection{Quantitative reverse transcription PCR (qRT-PCR)}

Bacterial and archaeal 16S rRNA gene copy numbers were determined by quantitative reverse-transcription PCR using the OneStep RT-PCR Kit (Qiagen, Hilden, Germany). The primer pairs 519f/907r and s D Arch 0025-a-S-17/s-D-Arch0344-a-S-20 were used to quantify bacterial and archaeal RNA, respectively. Primer sequences of these two domains are given in Wilms et al. (2007). Each $25 \mu \mathrm{l} \mathrm{PCR} \mathrm{reaction}$ contained $15.9 \mu \mathrm{l}$ nuclease-free water, $5 \times$ RT-PCR Buffer (Qiagen, Hilden, Germany), 0.4 mMdNTP Mix (Qiagen, Hilden, Germany), $0.2 \mu \mathrm{M}$ of each primer, $0.1 \mu \mathrm{l}$ of a 1:500 diluted SYBR Green I solution (Molecular Probes, Eugene, OR, USA), $1 \mu$ l One Step Enzyme Mix (Qiagen, Hilden, Germany) and $1 \mu \mathrm{l}$ standard $\left(10^{9}\right.$ to $10^{2}$ gene copies per $\left.\mu \mathrm{l}\right)$ or environmental target RNA. Thermal cycling comprised a reverse transcription step for $30 \mathrm{~min}$ at $50^{\circ} \mathrm{C}$, followed by an initial denaturation step for $15 \mathrm{~min}$ at $95^{\circ} \mathrm{C}, 40$ cycles of amplification $\left(10 \mathrm{~s}\right.$ at $94^{\circ} \mathrm{C}, 20 \mathrm{~s}$ at $54^{\circ} \mathrm{C}$ for bacterial RNA quantification or $48^{\circ} \mathrm{C}$ for archaeal RNA quantification, $30 \mathrm{~s}$ at $72^{\circ} \mathrm{C}$ and $20 \mathrm{~s}$ at $82^{\circ} \mathrm{C}$ ) and a terminal step $(2 \mathrm{~min}$ at $50^{\circ} \mathrm{C}$ ). After each run, a melting curve was recorded between $50^{\circ} \mathrm{C}$ and $99^{\circ} \mathrm{C}$ to ensure that only specific amplification had occurred.

As standards for bacterial gene targets, $16 \mathrm{~S}$ and $23 \mathrm{~S}$ ribosomal RNA of E. coli (Roche Diagnostics GmbH, GrenzachWyhlen, Germany) were used. A PCR product was used as standard for quantification of Archaea. Archaeal primer sequences and PCR conditions are given in Wilms et al. (2007). For each amplification the OneStep RT-PCR Kit was used according to the manufacturer's instructions. All PCRs contained a reverse transcription step $\left(30 \mathrm{~min}, 50^{\circ} \mathrm{C}\right)$ prior to amplification.

\section{Results}

The monitored microbial processes demonstrated similar trends in the degradation experiment and the untreated control. In contrast, the abiotic control showed no sign of sulfate reduction, methanogenesis, IPL degradation, fermentation or any other microbial activity as demonstrated by the stability of all measured parameters (data not shown).

\subsection{Sulfate and methane data}

Sulfate reduction and methanogenesis are terminal anaerobic mineralization processes. The concentrations of sulfate and methane were monitored to assess the current metabolic status of the experiment. Sulfate was completely consumed within the first 9 days (Fig. 2). Between day 9 and day 20, the sulfate concentration remained below the detection limit, until sulfate was refilled. Sulfate was replenished to mimic the natural environment. At the end of the experiment, sulfate was consumed more slowly than at the beginning, indicating the depletion of electron donors. The sulfate concentration decreased to $9 \mathrm{mM}$ on day 97 . Large amounts of methane were only detected in the absence of sulfate. The slightly decreasing values for sulfate consumption were in the range of the analytical error. The concentration of dissolved sulfide in the pore water remained relatively low $(6 \mathrm{mM})$ until day 27. The maximum concentration of $38 \mathrm{mM}$ was reached on day 76. Oxygen was never detected in any incubation vessel.

\subsection{Degradation of intact polar lipids}

The HPLC-MS chromatograms of the initial cell material of Saccharomyces cerevisiae and Haloferax volcanii showed characteristic signals for each organism (Fig. 3a and b). The IPL composition of the microbial community in the untreated control is different from those found in the added cells and showed a high variability (Fig. 3c). The characteristic signals of the added cell material were easily detectable in the 


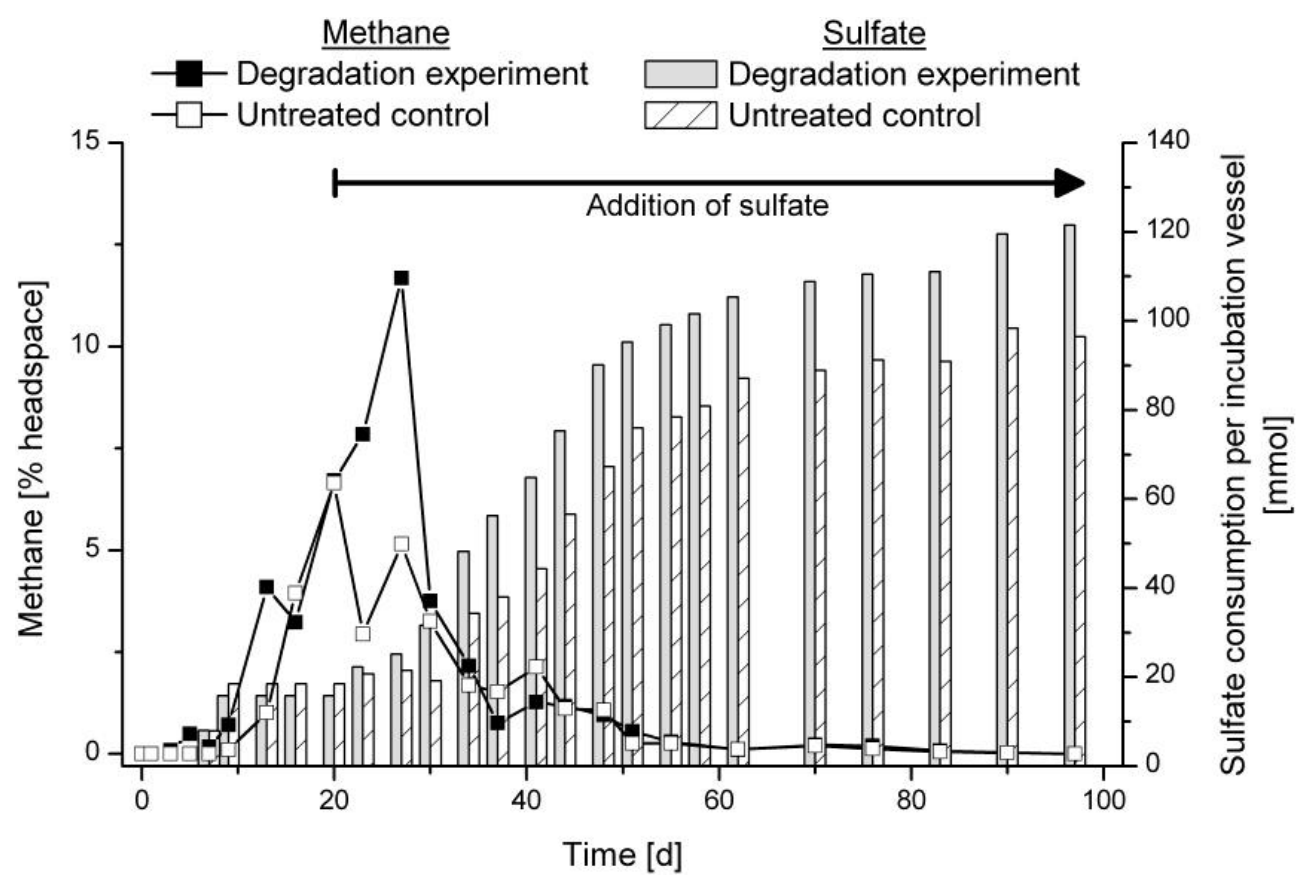

Fig. 2. Methane production and cumulative sulfate consumption in the degradation experiment and the untreated control. Sulfate consumption for each time point was calculated by addition of measured day-to-day losses. Methane concentrations are given in percentage of incubation vessel headspace. After day 20 sulfate was refilled when the concentration decreased below $10 \mathrm{mM}$ as indicated by the arrow.

degradation experiment (Fig. 3d). After an incubation period of 97 day substantial amounts of ester-bound IPLs of S. cerevisiae were degraded, whereas ether-bound IPLs of H. volcanii were still present (Fig. 3e).

The amounts of ester-bound IPLs decreased in the course of the experiment whereas those of ether-bound IPLs remained stable (Figs. 4-6). The head groups had no visible influence on the observed degradation pattern. The amounts of ester-bound IPLs with PC and PI head groups did not show any significant change in the first days of the degradation experiment. Beginning at day 5, they decreased rapidly over 5 days followed by a phase of moderate loss until day 90. In case of phosphatidylethanolamine-diacylglycerol (PE-DAG) and phosphatidylserine-diacylglycerol (PS-DAG) highest amounts were found on day 5 (Fig. $4 \mathrm{c}$ and d). Subsequently, the signal decreased over the rest of the experiment.

In contrast to this, the amounts of all ether-bound IPLs (Fig. 5) scattered but did not decrease significantly until the end of the degradation experiment. Ester- and ether-bound IPLs in the abiotic control showed behavior similar to each other with slightly decreasing values in the course of the experiment (Fig. 6). The amounts of IPLs in the degradation experiment increased within the first days while the abiotic control did not show this effect. The archaeal ether lipids in the degradation experiment remained elevated by about $50 \%$ relative to the abiotic control throughout the entire experiment.
Samples from the untreated control were taken in the same sampling intervals as in the degradation experiment. Most of the IPLs added to monitor the degradation were not detected in the untreated control. Exceptions were the IPLs PE-DAG 34:2 and PE-DAG 36:2, but compared to the corresponding PE-DAGs in the added biomass their total amount was low (less than 3\%). However, other IPLs such as sulfoquinovosyl diacylglycerol (SQ-DAG) and phosphatidylglycerol-diacylglcerol (PG-DAG) were identified in the untreated control. Additionally, PE-DAGs with side chains different from those in the degradation experiment were found (31:0, 31:1, 33:1, 33:2, 35:2). SQ-DAG was the most prominent IPL in the untreated control. It showed increasing abundance from day 0 to day 23 and then a decrease to the starting value at a moderate rate after a major drop between days 23 and 27. PE-DAG and PG-DAG showed an increase between day 0 and day 5 and returned to the starting values in the course of the experiment.

\subsection{IPL degradation rates}

The calculation of degradation rates for ester-bound IPLs resulted in a linear relation between $\log k^{\prime}$ and $\log$ time (Fig. 7). The $k^{\prime}$-values of ester-bound IPLs were higher than those of ether-bound IPLs reflecting the faster decreasing concentration of ester-bound IPLs (Fig. 6). Since the $k^{\prime}$-values are plotted logarithmically, an increase of one unit represents ten times faster degradation. Due to the scattered amounts of 

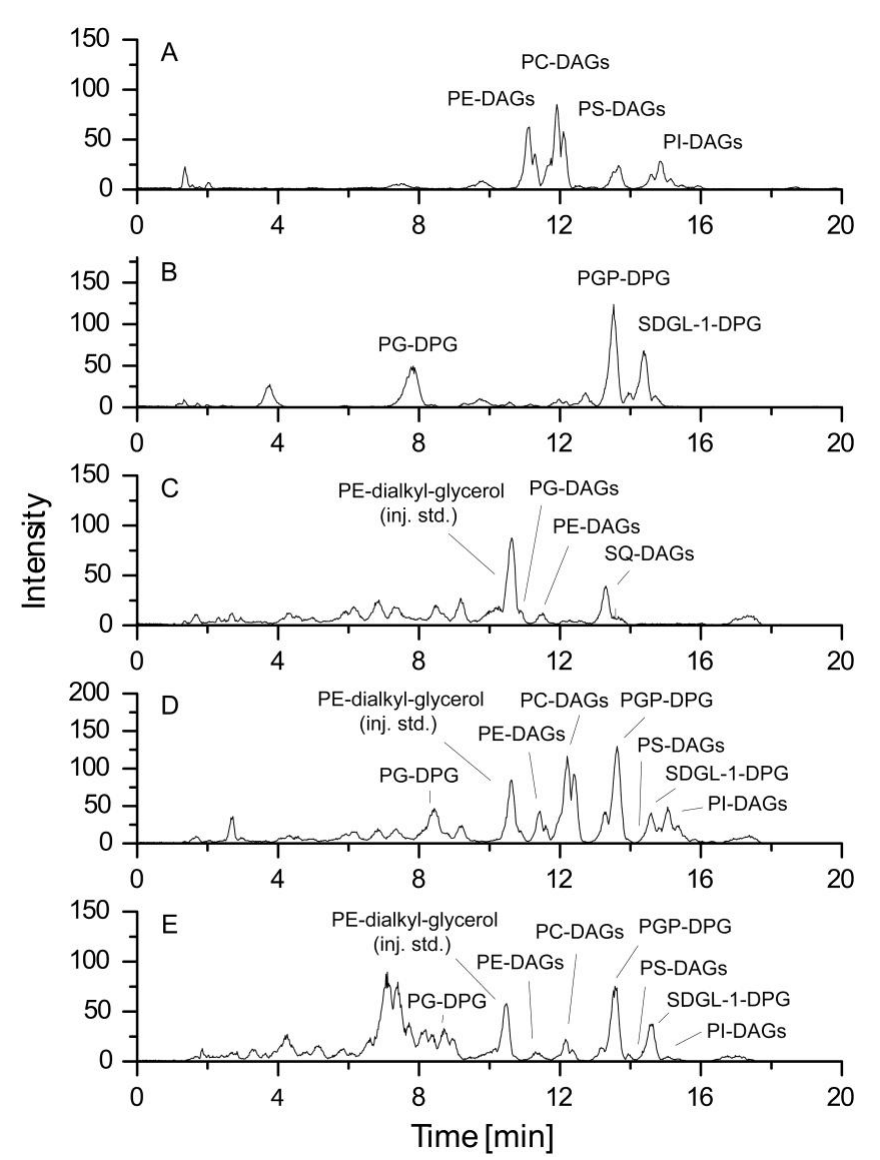

Fig. 3. HPLC-ESI-MS base-peak intensity (BPI) chromatograms in negative ion-mode of (A): total extract of Saccharomyces cerevisiae; (B): total extract of Haloferax volcanii; (C): total extract of the untreated control at day 0; (D): total extract of the degradation experiment, sample taken at day 0; $(\mathbf{E})$ : total extract of the degradation experiment, sample taken at day 97. For abbreviations see Fig. 1. Please note that the observed peak intensities cannot be directly transferred into concentrations.

ether-bound IPLs (Fig. 6), the relation for their kinetic degradation constants was less linear (Fig. 7).

\subsection{Succession in microbial abundance, diversity and activity}

The development of the microbial communities was monitored to obtain background information for the degradation of IPLs. The total cell counts of the degradation experiment and the untreated sediment showed the same trend and decreased only slightly during the experiment (Fig. 8). The total cell numbers of the degradation experiment were marginally higher than those of the untreated control. The numbers of bacterial 16S rRNA targets were one to two orders of magnitude higher than those of Archaea. Between days 7 and 16, the bacterial 16S rRNA copy numbers dropped significantly before returning to their previous values. The number of archaeal 16S rRNA copies showed a generally increasing trend. After day 20, the numbers of both bacterial and archaeal 16S rRNA targets remained relatively constant. The RNA content of the sediment ranged from 80 to $4800 \mathrm{ng} \mathrm{cm}^{-3}$. Ravenschlag et al. (2000) determined an rRNA content of 0.9 to $1.4 \mathrm{fg}$ rRNA per cell for two sulfate-reducing bacteria from surface sediments. These values were used to assess the total cell numbers of our study. The calculated values range between $8.9 \times 10^{7}$ and $3.4 \times 10^{9}$ cells cm$^{-3}$, which fits nicely to our total cell counts. The analysis of fermentation products showed no significant difference between the degradation experiment and the untreated control (Fig. S1). The bacterial community profiles of the degradation experiment and the untreated sediment looked similar to each other (Fig. S2). Initially, the community structure was highly diverse. This diversity decreased in the course of the experiment probably due to a diminishing substrate spectrum as indicated in Fig. S1.

The archaeal community pattern showed minor differences between the degradation experiment and the untreated control (Fig. S3). H. volcanii was only detected at the very first sampling point in the degradation experiment. In the beginning of the experiment, when sulfate was still present, no methanogenic archaea were detected (Fig. S3). Only after depletion of sulfate the rRNA of methanogens was found. The presence and activity of these organisms were supported by methane production observed in the absence of sulfate. In all samples, the content of eukaryotic RNA was too low to obtain sufficient PCR products to prepare a DGGE with eukaryotic primers.

\subsection{Total organic carbon}

The carbon content was analyzed at five time points of the degradation experiment and the untreated control. The difference between the degradation experiment and the untreated control reflected the amount of organic matter that was added to the degradation experiment with the inactive cell material of $S$. cerevisiae and $H$. volcanii. We added $1.36 \mathrm{~g}$ of cellderived organic carbon which increased the TOC content of the natural sediment from $0.23 \% \mathrm{C}_{\text {org }}(4.9 \mathrm{~g})$ to $0.29 \% \mathrm{C}_{\text {org }}$ $(6.2 \mathrm{~g})$. No pronounced difference was visible between the degradation experiment and the untreated control for all other parameters.

\subsection{Effects of sediment-derived organic matter on microbial processes}

The increasing amounts of fermentation products and total cell counts within the first week demonstrate a stimulation of microbial activity. This was likely caused by a temperature increase from $4{ }^{\circ} \mathrm{C}$ (storage temperature) to $20^{\circ} \mathrm{C}$ in the laboratory. The addition of biomass caused a faster increase of methanogenesis and fermentation. The added biomass also resulted in slightly increased rates of sulfate 

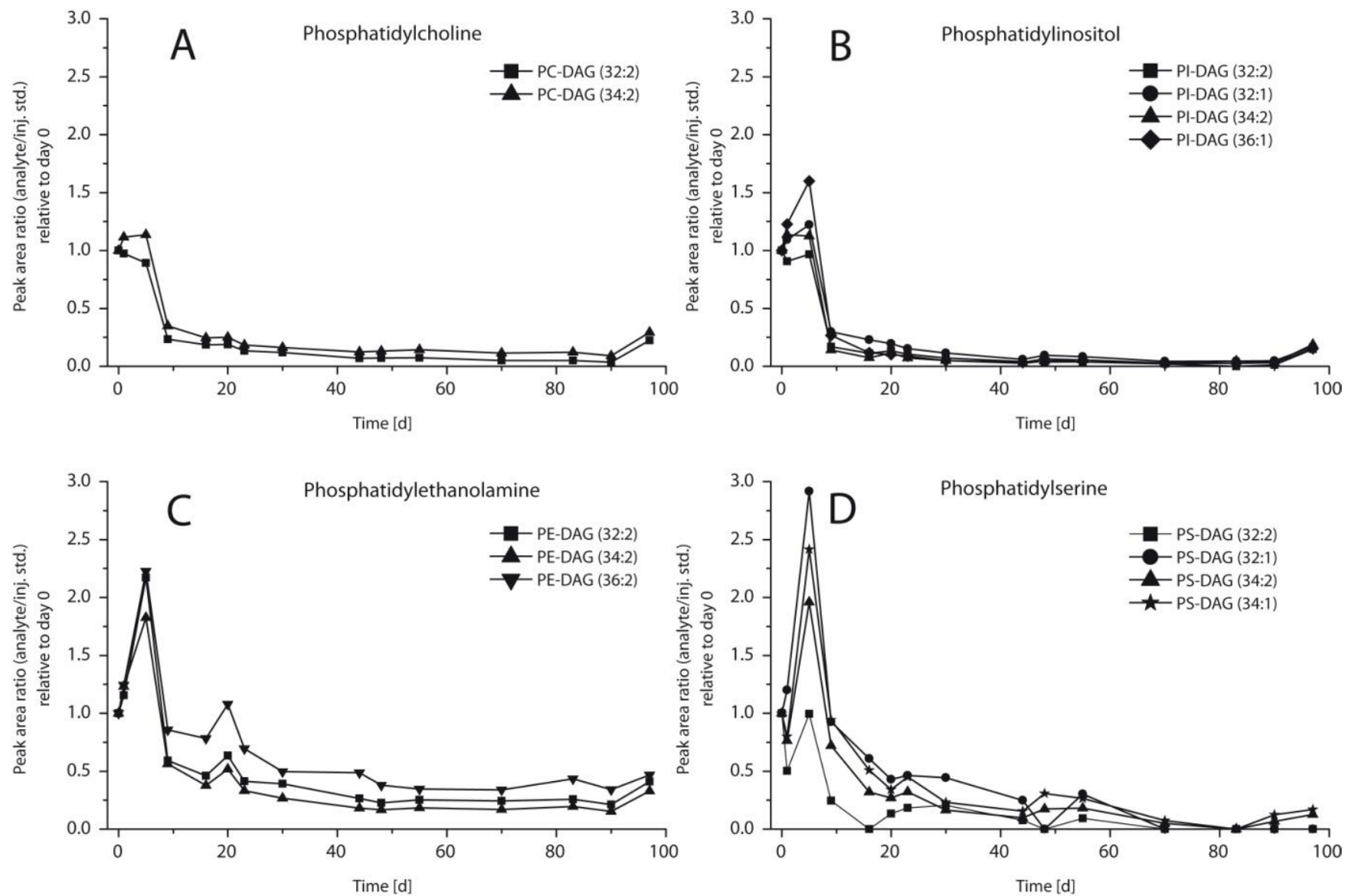

Fig. 4. Relative concentrations of ester-bound IPLs with different head groups in the degradation experiment vs. time in days (normalized to day 0 ). Core lipid structures are given as sum of fatty acids (e.g. 32:2) where 32 represents the number of carbon atoms and 2 represents the number of double bonds in the core lipid structure. See Fig. 1 for abbreviations.

consumption, methane production and fermentation (Figs. 2 and S1). Roughly $10 \%$ of the cellular dry weight consists of lipids (Stouthamer, 1979) and the IPL content is even lower. Therefore, the absolute amount of IPLs that were added with the biomass of $H$. volcanii and S. cerevisiae should have been low compared to other organic compounds present in the sediment itself. Accordingly, the fermentation products do not only reflect IPL degradation but mainly degradation of the organic matter inherited from the natural sediment (Fig. S1).

\section{Discussion}

In this experiment, ester-bound bacteria-like IPLs were degraded faster than ether-bound archaeal IPLs while an influence of the structure and the bonding type of the head group was not detected.

\subsection{Quality assessment of experimental design and data}

Haloferax volcanii and Saccharomyces cerevisiae do not occur naturally in tidal-flat sediments. Thus, it might be suspected that the observed degradation rates of IPLs turn out to be different from those of IPLs in the natural microbial community. However, the source of ether- and ester-bound IPLs should have no influence on the degradation rate since the chemical structures and the bonding types of the added material also occur naturally in IPLs found in Wadden Sea sediments (Rütters et al., 2001). Nevertheless, it is necessary to use cell material that is not indigenous to the sediment matrix to monitor the degradation of individual IPLs without confusing them with the inherited IPL inventory.

One could argue that the different degradation patterns observed for ether- and ester-bound IPLs are caused by a selective protection of ether-bound IPLs in intact $H$. volcanii cell material and on the other hand disrupted cells of $S$. cerevisiae. Membrane lipids in living organisms are protected by their surrounding cell walls. The outer surface of Haloferax volcanii consists of a hexagonally packed surface $(S)$ layer 


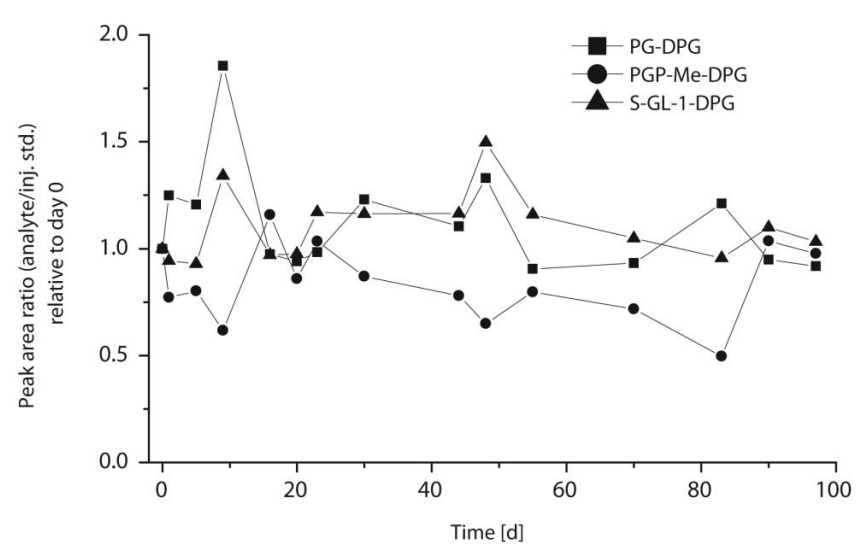

Fig. 5. Relative concentrations of ether-bound IPLs with different head groups in the degradation experiment vs. time in days (normalized to day 0). Abbreviations: sulfono diglyco dialkylglycerol (S-GL-1-DPG, according to Sprott et al., 2003), diphytanylglycerol (PG-DPG) and diphytanylglycerol methylphosphate (PGP-MeDPG).

glycoprotein (Sumper et al., 1990), whereas the cell wall of Saccharomyces cerevisiae consists mainly of glucan polymers, chitin and glycoproteins (Levin, 2005). Thus, the cell walls are likely to differ in stability. As archaeal S-layers are exceptionally stable, one might assume that the cells were still largely intact during the experiment and thus, the ether-bound lipids were not readily available for degradation. There are several arguments that this problem did not occur in our experimental set-up:

Although approximately $1 \times 10^{9} H$. volcanii cells ml $\mathrm{ml}^{-1}$ were added, no difference in total cell counts was observed between the degradation experiment and the untreated control at the beginning of the experiment.

The amount of archaeal 16S rRNA of the untreated control was even lower than in the degradation experiment at the beginning of degradation.

The RNA of $H$. volcanii was only detected at the very first sampling point of the experiment. The rapid degradation of the RNA indicates disintegration of the $H$. volcanii cells. RNA-based community analyses are often used to determine the active part of a community since the RNA content of cells can be correlated with cellular activity (Lee and Kemp, 1994; Wagner, 1994). However, stable isotope probing (SIP) experiments have shown that the RNA is detectable for days even when the microbes are not active (Graue et al., 2011). In our experiment we found RNA of sulfate-reducing bacteria in the absence of sulfate, supporting the finding that RNA is not degraded immediately when these organisms are inactive (Fig. S2).

Most importantly, however, the glycoprotein cell wall of halophilic archaea of the order Halobacteriales requires a high $\mathrm{NaCl}$ concentration for stability and cells almost instantaneously lyse in the absence of salt as described by Mohr and Larson (1963) and Kushner (1964). H. volcanii addi-

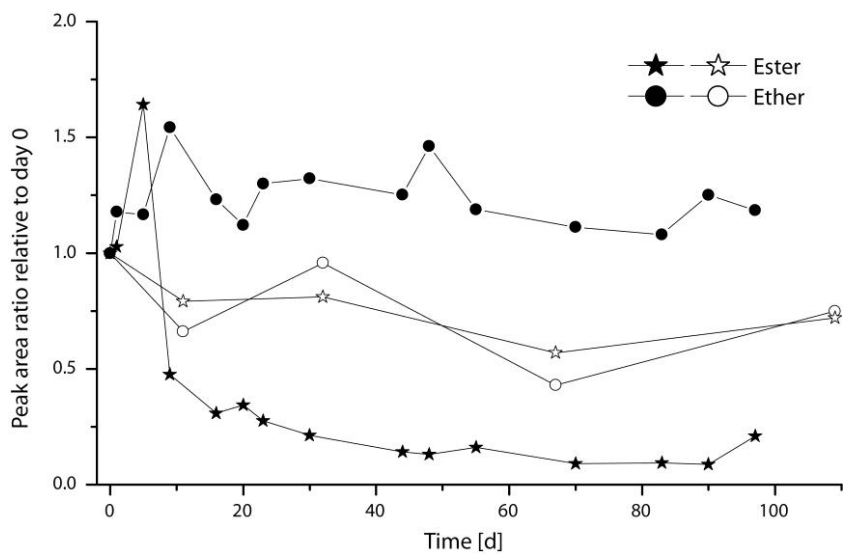

Fig. 6. Sum of ester- and ether-bound IPLs in the degradation experiment and the abiotic control given as relative concentrations normalized to day 0 . Closed symbols: degradation experiment; open symbols: abiotic control.

tionally requires high concentrations of magnesium (Cohen et al., 1983). As the $H$. volcanii cells were pasteurized in distilled water, it is unlikely that the cells remained intact.

Finally, cultivation attempts with pasteurized cells showed no growth which indicates that the $H$. volcanii cells were killed during the experiment. Thus, according to our line of argument it is very unlikely that the added biomass contained intact cells protecting IPLs from degradation.

If the degradative capacity of the microbial community is exceeded due to the high load of organic matter this would affect the degradation rates. However, high organic matter concentrations in Wadden Sea sediments are not unusual. They are caused e.g. by burial of algal blooms during storm events. In a study of Neira and Rackemann (1996) the degradation of algae biomass was investigated in situ. The amount of introduced total organic matter was 300 times higher than in our experiment. Nevertheless, the organic matter was degraded within two month. Even if the conditions of this study are not completely the same, we can assume that the degradative capacity in our study is not a limiting factor.

Comparing Figs. 4 and 5, different scattering patterns for ester- and ether-bound IPLs become apparent. The esterbound IPLs showed a strong increase from day 0 to 7 only for PE-DAGs (Fig. 4c) and PS-DAGs (Fig. 4d). This effect was not observed for PC-DAGs, PI-DAGs and ether-bound IPLs (Figs. 4a, b and 5, respectively). Additionally, the analysis of ether-bound IPLs showed non-systematic scattering. Adsorption/desorption processes of IPLs to/from the sediment matrix may be an issue. Different head groups lead to significant differences in chemical properties such as solubility, polarity and acidity. Changes in $\mathrm{pH}$ and redox potential influence adsorption/desorption processes and due to different chemical properties this may affect the investigated IPLs unequally. Sediment inhomogeneity is also a possible 


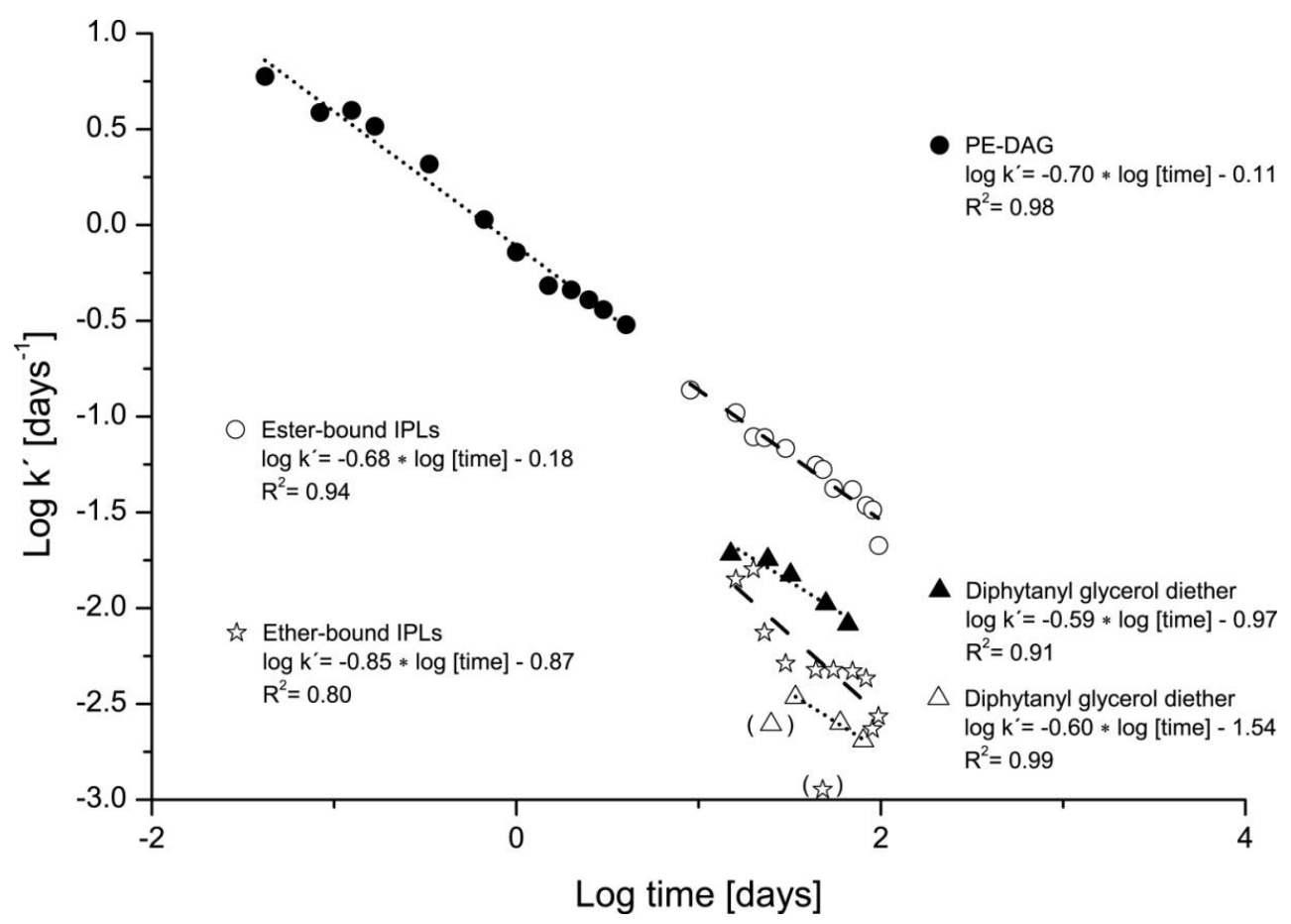

Fig. 7. Log-log plot of calculated kinetic degradation constants of ester-bound and ether-bound IPLs (dashed lines) with time in combination with three incubation experiments from Harvey et al. (1986, dotted lines). Closed symbols indicate aerobic degradation and open symbols anaerobic degradation. The plot was prepared as described by Schouten et al. (2010).

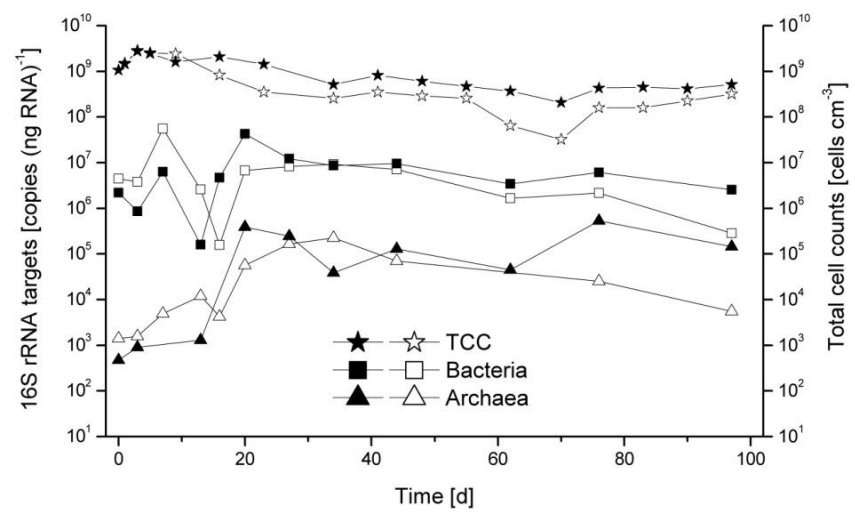

Fig. 8. Bacterial and archaeal $16 \mathrm{~S}$ rRNA copies and total cell counts (TCC) in the course of the experiment. The number of bacterial and archaeal 16S rRNA targets are given in copies per ng of extracted RNA, whereas the total cell counts are given in cells per $\mathrm{cm}^{3}$ sediment. Closed symbols: degradation experiment; open symbols: untreated control.

explanation. We tried to minimize this effect by the design of the incubation vessel and intense mixing prior to every sampling. In addition to this, the sediment was resuspended by shaking directly before opening the incubation vessels in the anaerobic chamber. Other reasons for scattering IPL values may be varying extraction efficiencies or changing matrix effects during ESI ionization.
There are several possible explanations for the elevated amounts of archaeal ether lipids in the degradation experiment relative to the abiotic control (Fig. 6). The higher values for ether-bound IPLs may be caused by the presentation of data normalizing to day 0 . If the sediment despite all caution was not completely homogenized during the first sampling, this affects all data points. Furthermore, the sediment of the abiotic control was autoclaved. This thermal treatment may have changed the structure of organic matter leading to a stronger adsorption. Another explanation may be that the microbial community in the degradation experiment has a positive effect on the release of adsorbed IPLs leading to a high recovery of those molecules. Nevertheless, all mentioned difficulties do not have any impact on the general results of this study.

\subsection{Influence of bonding types and structural moieties on IPL degradation}

Ester-bound IPLs are generally not only degraded by the hydrolysis of head groups but also by the hydrolysis of fatty acid side chains (Matos and Pham-Thi, 2009). Since the degradation pattern and hence the stability of all investigated ester-bound bacteria-like IPLs was approximately the same (Fig. 4a-d), it has to be considered that both the hydrolysis of head groups or side-chains might be responsible for their degradation patterns. In case of the archaeal lipids 
two structurally different bonding types of head groups were present - one glycosidic (S-GL-1) and two phosphoester (PG-DPG and PGP-Me-DPG; Fig. 1) head groups. However, the same degradation patterns were observed for both binding types. In general, compared to glycosidic bonds, phosphoester bonds are chemically more labile, since phosphoesters can be hydrolyzed by acids and bases whereas glycosidic bonds can usually only be hydrolyzed by acids (Beyer and Walter, 1991). Correspondingly, Harvey et al. (1986) found that glycosidic ether lipids were more stable than phospholipids with ester-bound moieties. However, they investigated the degradation of a glycosidic ether-bound lipid and a phosphoester ester-bound lipid. Thus, the study of Harvey et al. (1986) cannot be used to answer the question which part of an IPL-molecule (head group or moiety bonding type) is responsible for the observed differential stability of bacterial and archaeal IPLs.

According to our results, we assume that the differences in chemical stability of IPLs play only a minor role during the degradation of IPLs, at least in the investigated system. Since not only the head groups may have an influence on IPL degradation, also the structurally different core lipids have to be considered as possible factor for the observed degradation patterns. In general, complex molecules like lipids and proteins are hydrolyzed by exo- or ectoenzymes which are released by prokaryotic cells (Cypionka, 2010). Therefore, we conclude that microbiological enzymatic processes are the driving force in IPL degradation as also suggested by White et al. (1979) and Harvey et al. (1986) rather than expected chemical stabilities alone.

\subsection{IPL degradation rates}

The kinetic degradation constants of ester-bound IPLs (Fig. 7) in the beginning of our experiment are in the same range as those at the end of aerobic degradation of PEDAG in beach sediments observed by Harvey et al. (1986). Measured signal intensities in the degradation experiment on day 7 were as high as expected from the amount of added biomass. Therefore, significant degradation did not occur during the first 7 days. This means that the kinetic degradation constants of ester-bound IPLs in our experiment were significantly lower than those determined by Harvey et al. (1986).

In case of ether-bound IPLs the kinetic degradation constants determined in our study lie between those calculated for the ether-bound IPL with a glycosidic head group under oxic and anoxic conditions. In all cases this is in accordance to the common knowledge that the turnover of organic matter is aerobically faster than anaerobically.

\subsection{Microbial activity}

Originally, the experiment was also planned as an enrichment culture for lipid-degrading bacteria. It turned out, however, that the added cell material had only little influence on the community structure and the metabolic activity. This had a positive side-effect, since the processes which originally occur in tidal flat sediments were not disturbed and superposed. Therefore, the selected set-up is suitable to reflect the natural IPL degradation in such sediments. The increasing total cell counts in the beginning of the experiment were also visible in the untreated control and thus were probably caused by stimulation due to mixing and the higher temperature $\left(4^{\circ} \mathrm{C}\right.$ storage temperature and $20^{\circ} \mathrm{C}$ during the experiment).

Approximately $10 \%$ of the Archaea in Wadden Sea sediments are known to be methanogens (Wilms et al., 2007). They have a narrow substrate spectrum limited to simple molecules and are not known to degrade lipids. Probably, the main lipid degraders are Bacteria which are more abundant than Archaea in intertidal surface sediments (e.g. Beck et al., 2011). Anyhow, the physiological roles of most sedimentary archaea are not known (e.g. Teske and Sørensen, 2008) and therefore it cannot be excluded that they are also involved in the degradation of lipids.

Some studies indicate that Archaea use other enzymes than Bacteria to synthesize and degrade IPLs (Choquet et al., 1994; Daiyasu et al., 2005). The IPL degradation experiment was conducted with anoxic surface sediment which is dominated by bacteria affiliated to Proteobacteria, Actinobacteria, Bacteriodetes, Firmicutes, Spirochaetes and Chloroflexi, and archaea affiliated to Methanosarcinales, Thermococcales, Methanomicrobiales and Methanobacteriales (Wilms et al., 2006). The community structure of the deep biosphere, however, consists mainly of bacteria related to Chloroflexi, Gammaproteobacteria and JS1 candidate group and of archaea affiliated to the Miscellaneous Crenarchaeotic Group (MCG), Marine Benthic Group (MBG) and South African Goldmine Euryarchaeotal Group (SAGMEG) (Inagaki et al., 2006; Webster et al., 2006; Teske and Sørensen, 2008). As our results strongly suggest a microbial degradation of IPLs by enzymes, the community structure probably has a major influence on the degradation pattern. Thus, the observed degradation rates might be different if the experiment is repeated with sediment from the deep biosphere or in sediments where sulfate-reducing bacteria are not stimulated.

The question whether ester-bound lipids are recycled and used for membrane synthesis by Bacteria cannot be answered by our experimental-setup. Enzymes are described for Eukarya and Prokarya that facilitate bidirectional ATPindependent flipping of polar lipids across cytoplasmic membranes (Sanyal and Menon, 2009). The incorporation of extrinsic cell building blocks is energetically useful for microorganisms because it is more efficient to recycle existing molecules than to break them down to smaller molecules to synthesize them "de-novo". Takano et al. (2010) added ${ }^{13} \mathrm{C}$-labeled glucose to marine sediment and found that the ${ }^{13} \mathrm{C}$ was incorporated into the glycerol backbone of archaeal membrane lipids whereas the isoprenoid core lipids remained unlabeled. This indicates a recycling of comparable large 
membrane building blocks. To answer the question if IPLs can be recycled as intact molecules, stable-isotope probing (SIP) or ${ }^{14} \mathrm{C}$-labeling would be suitable tools to follow the degradation and incorporation of IPLs and their resulting products.

\subsection{DNA, RNA and intact polar lipids as biomarkers for living cells}

DNA and IPLs are commonly used as biomarkers for living cells (e.g. Biddle et al., 2006; Wilms et al., 2006). Additionally, RNA is used to determine the active part of microbial communities (e.g. Griffith et al., 2000). However, the successful application of these methods may be hampered by several aspects like varying extraction efficiencies, matrix effect and adsorption/desorption processes. The presence of DNA does neither prove the activity nor even the presence of the corresponding cells (Lorenz and Wackernagel, 1987; Josephson et al., 1993). In contrast, RNA is labile and the RNA content of cells can be correlated with cellular activity (Lee and Kemp, 1994; Wagner, 1994). However, when cells are inactive or have a very slow metabolism, the RNA content might not be sufficient for detection. The stability of ether-bound IPLs in our study suggests that IPLs also do not reflect exclusively the living community. This shows that none of the mentioned tools can be used without caution but a combination of these tools may help to get a more accurate picture.

\section{Conclusions}

The quantification of Bacteria and Archaea in the deep marine biosphere by IPL and FISH analysis led to the assumption that this habitat is dominated by Archaea (Biddle et al., 2006; Lipp et al., 2008). In contrast, catalyzed reporter deposition fluorescence in situ hybridization (CARD-FISH) and quantitative polymerase chain reaction (q-PCR) suggest a predominance of Bacteria (Schippers et al., 2005; Inagaki et al., 2006). Our experiment shows that these interpretations have to be considered with caution, since etherbound archaeal IPLs were clearly more stable than esterbound bacteria-like IPLs over a period of 100 days. In nature, ether-bound IPLs may even be preserved for longer time periods since the enhanced temperature in the laboratory accelerated the degradation processes.

To give better insights into the degradation of IPLs in other environments like the deep biosphere, it is desirable to conduct degradation experiments reflecting the in situ conditions of those habitats. For the deep biosphere this would mean that the experiments must be conducted under high pressure and over a long period since microbial turnover of organic matter is low. Furthermore, the addition of high substrate concentration would lead to a distorted image of ongoing processes as the in situ available organic matter is recalcitrant.

On the other hand, IPL-based quantification may lead to an overestimation of archaeal cell counts as indicated by our study. Regarding the discussion above, molecular biological methods based on DNA or RNA can also be inaccurate. Thus, the abundances of Archaea and Bacteria obtained with both methods have to be interpreted with caution.

\section{Supplementary material related to this article is available online at: http://www.biogeosciences.net/8/2547/2011/ bg-8-2547-2011-supplement.pdf.}

Acknowledgements. The authors are grateful to B. Kopke, B. Buchmann, H. Haase and P. Neumann for their technical assistance. Many thanks to Michael Seidel for sharing his experience in IPL degradation experiments that were conducted prior to this work. We thank K.-U. Hinrichs, A. Schippers and two anonymous referees for their constructive comments and suggestions. This work was financially supported by Deutsche Forschungsgemeinschaft (DFG) within the Research Group on "BioGeoChemistry of Tidal Flats" (FOR 432).

Edited by: K. Suzuki

\section{References}

Adams, A. E. M., Johnson, D. I., Longnecker, R. M., Sloat, B. F., and Pringle, J. R.: $C D C 42$ and $C D C 43$, two additional genes involved in budding and establishment of cell polarity in the yeast Saccharomyces cerevisiae, J. Cell Biol., 111, 131-142, 1990.

Beck, M., Riedel, T., Graue, J., Köster, J., Kowalski, N., Wu, C. S., Wegener, G., Lipsewers, Y., Freund, H., Böttcher, M. E., Brumsack, H.-J., Cypionka, H., Rullkötter, J., and Engelen, B.: Imprint of past and present environmental conditions on microbiology and biogeochemistry of coastal Quaternary sediments, Biogeosciences, 8, 55-68, doi:10.5194/bg-8-55-2011, 2011.

Beyer, H. and Walter, W.: Lehrbuch der Organischen Chemie, 22. Auflage, S. Hirzel Verlag, Stuttgart, 1-1030, 1991.

Biddle, J. F., Lipp, J. S., Lever, M. A., Lloyd, K. G., Sørensen, K. B., Anderson, R., Fredricks, H. F., Elvert, M., Kelly, T. J., Schrag, D. P., Sogin, M. L., Brenchley, J. E., Teske, A., House, C. H., and Hinrichs, K. U.: Heterotrophic archaea dominate sedimentary subsurface ecosystems off Peru, P. Natl. Acad. Sci. USA, 103, 3846-3851, 2006.

Boschker, H. T. S., Nold, S. C., Wellsbury, P., Bos, D., de Graaf, W., Pel, R., Parkes, R. J., and Cappenberg, T. E.: Direct linking of microbial populations to specific biogeochemical processes by ${ }^{13}$ C-labelling of biomarkers, Nature, 392, 801-805, 1998.

Boumann, H. A., Hopmans, E. C., van de Leemput, I., Op den Camp, H. J. M., van de Vossenberg, J., Strous, M., Jetten, M. S. M., Damste, J. S. S., and Schouten, S.: Ladderane phospholipids in anammox bacteria comprise phosphocholine and phosphoethanolamine headgroups, FEMS Microbiol. Lett., 258, 297304, 2006. 
Choquet, C. G., Patel, G. B., Beveridge, T. J., and Sprott, G. D.: Stability of pressure extruded liposomes made from archaebacterial ether lipids, Appl. Microbiol. Biot., 42, 375-384, 1994.

Cohen, S., Oren, A., and Shilo, M.: The divalent cation requirement of Dead Sea halobacteria, Arch. Microbiol., 136, 184-190, 1983.

Cord-Ruwisch, R.: A quick method for the determination of dissolved and precipitated sulfides in cultures of sulfate-reducing bacteria, J. Microbiol. Meth., 4, 33-36, 1985.

Cypionka, H.: Grundlagen der Mikrobiologie, Auflage 4, Springer, Heidelberg, 1-337, 2010.

Daiyasu, H., Kuma, K.-I., Yokoi, T., Morii, H., Koga, Y., and Toh, H.: A study of archaeal enzymes involved in polar lipid synthesis linking amino acid sequence information, genomic contexts and lipid composition, Archaea, 1, 399-410, 2005.

Ertefai, T. F., Fisher, M. C., Fredricks, H. F., Lipp, J. S., Pearson, A., Birgel, D., Udert, K. M., Cavanaugh, C. M., Gschwend, P. M., and Hinrichs, K. U.: Vertical distribution of microbial lipids and functional genes in chemically distinct layers of a highly polluted meromictic lake, Org. Geochem., 39, 1572-1588, 2008.

Graue, J., Engelen, B., and Cypionka, H.: Degradation of cyanobacterial biomass in anoxic tidal-flat sediments: A microcosm study of metabolic processes and community changes, ISME J., doi:10.1038/ismej.2011.120, in press, 2011.

Griffiths, R. I., Whiteley, A. S., O’Donnell, A. G., and Bailey, M. J.: Rapid method for coextraction of DNA and RNA from natural environments for analysis of ribosomal DNA- and rRNA-based microbial community composition, Appl. Environ. Microbiol., 66, 5488-5491, 2000.

Harvey, H. R., Fallon, R. D., and Patton, J. S.: The effect of organicmatter and oxygen on the degradation of bacterial membrane lipids in marine sediments, Geochim. Cosmochim. Ac., 50, 795$804,1986$.

Inagaki, F., Nunoura, T., Nakagawa, S., Teske, A., Lever, M., Lauer, A., Suzuki, M., Takai, K., Delwiche, M., Colwell, F. S., Nealson, K. H., Horikoshi, K., D'Hondt, S., and Jørgensen, B. B.: Biogeographical distribution and diversity of microbes in methane hydrate-bearing deep marine sediments on the Pacific Ocean Margin, P. Natl. Acad. Sci. USA, 103, 2815-2820, doi:10.1073/pnas.0511033103, 2006.

Jaeschke, A., Rooks, C., Trimmer, M., Nicholls, J. C., Hopmans, E. C., Schouten, S., and Damste, J. S. S.: Comparison of ladderane phospholipid and core lipids as indicators for anaerobic ammonium oxidation (anammox) in marine sediments, Geochim. Cosmochim. Ac., 73, 2077-2088, doi:10.1016/j.gca.2009.01.013, 2009.

Josephson, K. L., Gerba, C. P., and Pepper, I. L.: Polymerase chain reaction detection of nonviable bacterial pathogens, Appl. Environ. Microbiol., 59, 3513-3515, 1993.

Kushner, D. J.: Lysis and dissolution of cells and envelopes of an extremely halophilic bacterium, J. Bacteriol., 87, 1147-1156, 1964.

Lee, S. H. and Kemp, P. F.: Single-cell RNA-content of natural marine planktonic bacteria measured by hybridization with multiple 16S ribosomal-RNA-targeted fluorescent-probes, Limnol. Oceanogr., 39, 869-879, 1994.

Levin, D. E.: Cell wall integrity signaling in Saccharomyces cerevisiae, Microbiol. Mol. Biol. R., 69, 262-291, 2005.

Lin, Y. S., Lipp, J. S., Yoshinaga, M. Y., Lin, S. H., Elvert, M., and Hinrichs, K. U.: Intramolecular stable carbon isotopic analysis of archaeal glycosyl tetraether lipids, Rapid Commun. Mass Sp., 24, 2817-2826, doi:10.1002/rcm.4707, 2010.

Lipp, J. S. and Hinrichs, K. U.: Structural diversity and fate of intact polar lipids in marine sediments, Geochim. Cosmochim. Ac., 73, 6816-6833, 2009.

Lipp, J. S., Morono, Y., Inagaki, F., and Hinrichs, K.-U.: Significant contribution of Archaea to extant biomass in marine subsurface sediments, Nature, 454, 991-994, doi:10.1038/nature07174, 2008.

Lorenz, M. G. and Wackernagel, W.: Adsorption of DNA to sand and variable degradation rates of adsorbed DNA, Appl. Environ. Microbiol., 53, 2948-2952, 1987.

Lunau, M., Lemke, A., Walther, K., Martens-Habbena, W., and Simon, M.: An improved method for counting bacteria from sediments and turbid environments by epifluorescence microscopy, Environ. Microbiol., 7, 961-968, 2005.

Matos, A. R. and Pham-Thi, A. T.: Lipid deacylating enzymes in plants: Old activities, new genes, Plant Physiol. Bioch., 47, 491503, doi:10.1016/j.plaphy.2009.02.011, 2009.

Mohr, V. and Larsen, H.: On the structural transformations and lysis of Halobacterium salinarium in hypotonic and isotonic solutions, J. Gen. Microbiol., 31, 267-280, 1963.

Mullakhanbhai, M. F. and Larsen, H.: Halobacterium volcanii spec. nov., a Dead Sea halobacterium with a moderate salt requirement, Arch. Microbiol., 104, 207-214, 1975.

Neira, C. and Rackemann, M.: Black spots produced by buried macroalgae in intertidal sandy sediments of the Wadden Sea: Effects on the meiobenthos, J. Sea Res., 36, 153-170, doi:10.1016/s1385-1101(96)90786-8, 1996.

Ravenschlag, K., Sahm, K., Knoblauch, C., Jørgensen, B. B., and Amann, R.: Community structure, cellular rRNA content, and activity of sulfate-reducing bacteria in marine arctic sediments, Appl. Environ. Microbiol., 66, 3592-3602, doi:10.1128/aem.66.8.3592-3602.2000, 2000.

Rossel, P. E., Lipp, J. S., Fredricks, H. F., Arnds, J., Boetius, A., Elvert, M., and Hinrichs, K. U.: Intact polar lipids of anaerobic methanotrophic archaea and associated bacteria, Org. Geochem., 39, 992-999, doi:10.1016/j.orggeochem.2008.02.021, 2008.

Rütters, H., Sass, H., Cypionka, H., and Rullkötter, J.: Monoalkylether phosphoslipids in the sulfate-reducing bacteria Desufosarcina variablis and Desulforhabus amnigenus, Arch. Microbiol., 176, 435-442, 2001.

Sanyal, S. and Menon, A. K.: Flipping Lipids: Why an' What's the Reason for?, ACS Chem. Biol., 4, 895-909, doi:10.1021/cb900163d, 2009.

Schippers, A., Neretin, L. N., Kallmeyer, J., Ferdelman, T. G., Cragg, B. A., Parkes, R. J., and Jørgensen, B. B.: Prokaryotic cells of the deep sub-seafloor biosphere identified as living bacteria, Nature, 433, 861-864, 2005.

Schouten, S., Middelburg, J. J., Hopmans, E. C., and Sinninghe Damsté, J. S.: Fossilization and degradation of intact polar lipids in deep subsurface sediments: A theoretical approach, Geochim. Cosmochim. Ac., 74, 3806-3814, 2010.

Schubotz, F., Wakeham, S. G., Lipp, J. S., Fredricks, H. F., and Hinrichs, K.-U.: Detection of microbial biomass by intact polar membrane lipid analysis in the water column and surface sediments of the Black Sea, Environ. Microbiol., 11, 2720-2734, 2009.

Sprott, G. D., Larocque, S., Cadotte, N., Dicaire, C. J., McGee, 
M., and Brisson, J. R.: Novel polar lipids of halophilic eubacterium Planococcus $\mathrm{H} 8$ and archaeon Haloferax volcanii, BBAMol. Cell Biol. L., 1633, 179-188, 2003.

Stouthamer, A. H.: The search for correlation between theoretical and experimental growth yields, Int. Rev. Biochem, 21, 1-15, 1979.

Sturt, H. F., Summons, R. E., Smith, K., Elvert, M., and Hinrichs, K. U.: Intact polar membrane lipids in prokaryotes and sediments deciphered by high-performance liquid chromatography/electrospray ionization multistage mass spectrometry - new biomarkers for biogeochemistry and microbial ecology, Rapid Commun. Mass Sp., 18, 617-628, 2004.

Sumper, M., Berg, E., Mengele, R., and Strobel, I.: Primary structure and glycosylation of the S-layer protein of Haloferax volcanii, J. Bacteriol., 172, 7111-7118, 1990.

Takano, Y., Chikaraishi, Y., Ogawa, N. O., Nomaki, H., Morono, Y., Inagaki, F., Kitazato, H., Hinrichs, K. U., and Ohkouchi, N.: Sedimentary membrane lipids recycled by deep-sea benthic archaea, Nat. Geosci., 3, 858-861, doi:10.1038/ngeo983, 2010.

Teske, A. and Sørensen, K. B.: Uncultured archaea in deep marine subsurface sediments: have we caught them all?, ISME J., 2, 3$18,2008$.

Van Mooy, B. A. S., Fredricks, H. F., Pedler, B. E., Dyhrman, S. T., Karl, D. M., Koblizek, M., Lomas, M. W., Mincer, T. J., Moore, L. R., Moutin, T., Rappe, M. S., and Webb, E. A.: Phytoplankton in the ocean use non-phosphorus lipids in response to phosphorus scarcity, Nature, 458, 69-72, 2009.
Wagner, R.: The regulation of ribosomal-RNA synthesis and bacterial-cell growth, Arch. Microbiol., 161, 100-109, 1994.

Webster, G., Parkes, R. J., Cragg, B. A., Newberry, C. J., Weightman, A. J., and Fry, J. C.: Prokaryotic community composition and biogeochemical processes in deep subseafloor sediments from the Peru Margin, FEMS Microbiol. Ecol., 58, 65-85, doi:10.1111/j.1574-6941.2006.00147.x, 2006.

White, D. C., Davis, W. M., Nickels, J. S., King, J. D., and Bobbie, R. J.: Determination of the sedimentary microbial biomass by extractable lipid phosphate, Oecologia, 40, 51-62, 1979.

Wilms, R., Sass, H., Kopke, B., Koster, J., Cypionka, H., and Engelen, B.: Specific Bacterial, Archaeal, and Eukaryotic Communities in Tidal-Flat Sediments along a Vertical Profile of Several Meters, Appl. Environ. Microbiol., 72, 2756-2764, doi:10.1128/aem.72.4.2756-2764.2006, 2006.

Wilms, R., Sass, H., Köpke, B., Cypionka, H., and Engelen, B.: Methane and sulfate profiles within the subsurface of a tidal flat are reflected by the distribution of sulfate-reducing bacteria and methanogenic archaea, FEMS Microbiol. Ecol., 59, 611-621, 2007.

Zink, K. G., Wilkes, H., Disko, U., Elvert, M., and Horsfield, B.: Intact phospholipids - microbial "life markers" in marine deep subsurface sediments, Org. Geochem., 34, 755-769, 2003. 